\title{
PORTUGUÊS COMO LÍNGUA ADICIONAL NO PROGRAMA IDIOMAS SEM FRONTEIRAS NA UNICAMP: INTERNACIONALIZAÇÃO E POLÍTICAS LINGUÍSTICAS EM FOCO
}

\author{
Portuguese as an Additional Language and the Languages without Borders \\ Program at Unicamp: Internationalization and Language Policy in the \\ Spotlight
}

\author{
Bruna Elisa FRAZATTO \\ Universidade Estadual de Campinas \\ brunafrazatto@gmail.com \\ https://orcid.org/0000-0001-6649-4718
}

RESUMO: O objetivo deste artigo é analisar como mecanismos de política linguística (SHOHAMY, 2006) podem repercutir nos projetos de internacionalização da educação superior, criando políticas linguísticas de facto. Para isso, parto da criação do programa Inglês sem Fronteiras (subsequentemente, Idiomas sem Fronteiras), e analiso o cenário que se desenha na Universidade Estadual de Campinas, principalmente a partir do Núcleo de Línguas do programa e dos cursos de português como língua adicional lá oferecidos. A discussão traz à tona a necessidade de se pensar no contexto local para operacionalizar não só políticas linguísticas, mas também políticas de internacionalização, numa perspectiva solidária.

PALAVRAS-CHAVE: Português como Língua Adicional; Internacionalização; Política Linguística; Idiomas sem Fronteiras.

\begin{abstract}
The aim of this paper is to analyze how language policy mechanisms (SHOHAMY, 2006) might impact on higher education internationalization projects, creating de facto language policies. To pursue that aim, I depart from the creation of the English without Borders (later on, Languages without Borders) program to analyze the scenario designed at Campinas State University, focusing particularly on the program's Language Center (Núcleo de Línguas) and its Portuguese as an Additional Language courses. The discussion brings to light the need to address local contexts in order to operationalize, from a solidary perspective, not only language policy, but also internationalization policies.

KEYWORDS: Portuguese as an Additional Language; Internationalization; Language Policy; Languages without Borders.
\end{abstract}




\section{INTRODUÇÃO}

Em tempos de globalização hegemônica (SANTOS, 2002), não é surpreendente que seus efeitos estejam presentes, em alguma medida, em discursos e práticas sobre/na língua(gem), oficiais ou não, nos contextos educacionais e acadêmicos. Podem-se mencionar, na educação básica, versões de documentos como a Base Nacional Comum Curricular (BNCC), que preveem um ensino homogêneo ao longo do vasto território brasileiro, ou ainda, na educação superior, projetos de internacionalização pautados por uma ilusão de homogeneidade universal.

Com relação ao ensino superior, embora a complexidade do processo de internacionalização venha sendo discutida há algum tempo (BIZON, 2013; KNIGHT, 2014, 2015a, 2015b; J. MARTINEZ, 2017; C. MARTINEZ, 2018), ainda é possível encontrar, em grande parte das instituições brasileiras e estrangeiras, projetos de internacionalização operacionalizados via ações que se resumem à mera ampliação da mobilidade discente e docente. A ideia de que tais ações resultariam automaticamente em internacionalização é o que Knight (2015a) descreve como alguns dos mitos da internacionalização.

Compondo o cenário da internacionalização do ensino superior, uma das políticas públicas brasileiras de destaque foi o programa Idiomas sem Fronteiras (IsF), que, como abordarei, repercutiu no desenvolvimento e na maior atenção ao campo das políticas linguísticas (FINARDI; GUIMARÃES, 2017), comumente deixado de lado nas discussões sobre internacionalização anteriores ao programa. Apesar disso, conforme informações disponíveis no site do próprio $\mathrm{IsF}^{1}$, ainda são poucas pesquisas que focalizam o ensino de português ou das outras línguas promovido pelos Núcleos de Línguas (NucLis) do programa IsF, o que reforça a presença do ensino-aprendizagem de inglês, bem como sua dominância nas ações de internacionalização.

A fim de fomentar discussões envolvendo outras línguas do IsF, o objetivo deste artigo é propor uma análise inicial do cenário da política linguística do português como

Cf. Produções e Pesquisas sobre o Programa. Idiomas sem Fronteiras. Disponível em: $<$ http://isf.mec.gov.br/pesquisas-e-relatorios/33-pesquisas-e-relatorios/200-producoes-e-pesquisas $>$. Acesso em: 27 mar. 2020. 
língua adicional (PLA) ${ }^{2}$ e da internacionalização na Universidade Estadual de Campinas (Unicamp) de forma a compreender melhor como os chamados mecanismos de política linguística (SHOHAMY, 2006), como alguns cursos oferecidos pelo NucLi-IsF nessa instituição, podem repercutir nos projetos de internacionalização da universidade, criando políticas linguísticas na prática e vindo a impactar a inserção de alunos/pesquisadores internacionais.

Discuto, na primeira seção, a necessidade de refletirmos sobre os significados atribuídos à internacionalização. Na segunda, abordo o campo das políticas linguísticas, priorizando os conceitos de mecanismo e políticas linguísticas educacionais (SHOHAMY, 2006), e onde se situa esse campo na discussão sobre internacionalização. Na terceira, de forma macro, trago um breve histórico do IsF e seus desdobramentos, chegando, na quarta seção, ao contexto micro da Unicamp, no qual apresento seus cursos de PLA e o papel de algumas práticas do NucLi-IsF. Nestas seções ficará clara não só a importância das políticas linguísticas oficiais, mas também de outras ações que surgem das necessidades. Por fim, apresento considerações e encaminhamentos para pesquisas futuras.

\section{O QUE SIGNIFICA INTERNACIONALIZAR?}

É a partir da compreensão do fazer científico como prática política e problematizadora, inclusive de seu próprio fazer (PENNYCOOK, 2001; CAVALCANTI, 2006; BIZON, 2013), que surge a pergunta-título desta seção. Diante do cenário aparentemente tão internacionalizado nos materiais de divulgação das instituições de ensino superior, na mídia, nas pesquisas científicas, a pergunta não quer calar. Segundo Sampaio (2016), a internacionalização como área de estudos aparece por volta da década de 1990 na América Latina. Entretanto, tentando fazer um balanço das pesquisas sobre a internacionalização do ensino superior no Brasil, no México e na Argentina, a autora comenta que, até os anos 2000, os trabalhos versavam prioritariamente sobre o termo

\footnotetext{
${ }^{2}$ Embora português como língua estrangeira (PLE) ainda seja o termo mais usado no Brasil, usarei português como língua adicional (PLA) ao longo deste artigo, em concordância com a noção de língua que se desenvolve em diferentes âmbitos de pesquisa e de ensino. Em discussão aprofundada, Jordão (2014) argumenta que o uso de LE carrega consigo uma oposição à língua nativa, portanto remetendo à ideia de língua como sistema fixo, à "competência" de falante nativo que deveria ser alcançada por falantes nãonativos, enquanto língua adicional se caracterizaria por alçar o plurilinguismo à discussão e considerar o repertório já existente do falante. Neste artigo, PLE aparecerá somente no título de uma disciplina do NucLiIsF/Unicamp.
} 
cooperação internacional, o que denotaria uma transformação na configuração do que se considerava internacionalização ou não.

O termo internacionalização, discorre Knight (2015a, p.14), vem tendo seu sentido esvaziado, sendo usado "para descrever toda e qualquer coisa remotamente relacionada ao mundial, intercultural, global ou internacional ${ }^{33}$ ". Considero, como diversos autores (DE WIT, 2016; STEIN et al., 2016), que a internacionalização pode ser pensada e conduzida de várias formas, fazendo emergir diferentes discursos sobre o que significa internacionalizar. Seguindo Andreotti, Pereira e Edmundo (2017) e Martinez (2017), para se pensar os significados da internacionalização, é necessário também pensar no papel da educação e nos efeitos que a relação entre elas pode provocar, considerando, como explicita Martinez (2017), o emaranhado da linha da colonialidade com a linha da nova ordem mundial.

A nova ordem mundial, produto do que Santos (2002) chama de globalização hegemônica, seria responsável pelo que constitui o "discurso oficial da internacionalização", como a quantificação do conhecimento e a obsessão pelas métricas (SANTOS, 2016). Embora globalização e internacionalização não sejam a mesma coisa ${ }^{4}$, Martinez (2017, p. 17) aponta que "a força do discurso oficial da internacionalização surge atrelada à ideia de globalização presente no senso comum da atualidade". Para elucidar como isso ocorre, a autora explica que aquilo usualmente compreendido como internacionalização é naturalizado pelos localismos globalizados e globalismos localizados (SANTOS, 2002), modos de produção da globalização hegemônica. Para exemplificar, assim como toda globalização pressupõe localização, o discurso oficial de internacionalização também produz, simultaneamente, a localização das universidades que não atingem esse patamar. Perdura também, muitas vezes, a ideia da necessidade do fluxo de pessoas (e de informações) no espaço-tempo, o qual é frequentemente gerenciado de maneira burocrática e através da linha da colonialidade: criam-se hierarquias, seja por rankings internacionais, áreas de estudo, agências de fomento e/ou línguas "dominantes". Nesses "fios emaranhados" (MARTINEZ, 2017), não existe uma linha sem a outra, pois a internacionalização em curso em grande parte das universidades, principalmente no Norte

\footnotetext{
${ }^{3}$ Todas as traduções são minhas. No original: "it is now used to describe anything and everything remotely linked to worldwide, intercultural, global, or international."

${ }^{4}$ Cf. BIZON, 2013; MARTINEZ, 2017.
} 
Global $^{5}$, insiste em um modelo de déficit claramente baseado na colonialidade da educação superior.

$\mathrm{Na}$ tentativa de quebrar com esse modelo colonial e neoliberal e pensar outras formas de internacionalizar, torna-se importante considerar o que afirma Knight (2015b, p.3) sobre o processo de internacionalização não ser um fim em si mesmo, mas se integrar “de forma sustentável aos propósitos essenciais de ensino e aprendizagem da educação superior, da pesquisa e produção de conhecimento, e da extensão para a comunidade e sociedade ${ }^{6,}$.

Ao contrário do que é reforçado, por exemplo, por rankings internacionais, divulgados e vistos como parâmetros de sucesso (ou insucesso) de nossas universidades, seria importante realizar a internacionalização baseando-se nas necessidades de cada local (KNIGHT, 2014, 2015b; DE WIT, 2016). Vale ressaltar ainda que, além da mobilidade, há muitas ações que podem fazer parte da internacionalização, tais como ensino de línguas, auxílio na produção de escrita acadêmica, atividades para inserção e acolhimento de estudantes internacionais e nacionais (retornados de intercâmbio) e preparação do corpo docente/técnico-administrativo para parcerias nacionais e internacionais.

Numa perspectiva da Linguística Aplicada Crítica (PENNYCOOK, 2001), que se engaja socialmente, internacionalizar teria de se afastar da

tendência de instituições de ensino operarem como grandes centros administrativos, em que a ânsia pelo crescimento e reconhecimento internacional acaba, muitas vezes, sobrepondo-se a preceitos éticos que envolvem a formação do cidadão e que nunca deveriam estar subjugados aos interesses do capital político de gerenciamento da produção científico-intelectual (BIZON, 2013, p. 44).

Assim, haveria possibilidade de uma "internacionalização solidária" (SANTOS, 2016) em nossas instituições. Essa alternativa, ao desconstruir hierarquias e resistir a planos de ação movidos pela mercantilização do conhecimento, passaria a colocar em destaque a cooperação e o diálogo com diferentes atores, implicando trazer para os cenários não

\footnotetext{
${ }^{5}$ Segundo Santos (2002, p. 52), mais do que localização geográfica, “o importante é analisar em cada país ou região a ratio entre inclusão e exclusão", isto é, o Sul poderia estar localizado no território de um país do Norte, e vice-versa, constituindo-se, na verdade, como um conceito geopolítico.

6 "in a sustainable manner into the major functions of higher education teaching and learning, research and knowledge production, and service to the community and society."
} 
apenas parceiros e epistemologias de países centrais, mas também de países periféricos e semiperiféricos.

\section{POLÍTICA LINGUÍSTICA E INTERNACIONALIZAÇÃO}

Embora o contato e o convívio entre comunidades acadêmicas de diferentes locais sejam uma das possibilidades da internacionalização, ainda há pouco destaque para o papel crucial que o ensino-aprendizagem de línguas e os departamentos de língua podem desempenhar no processo e nas políticas de internacionalização (BIZON, 2013; DLASKA, 2013). Tais autoras têm argumentado pela necessidade de que projetos de internacionalização tenham políticas públicas eficientes nessa área. A internacionalização, conduzida da forma que for, pressupõe políticas linguísticas, pois, como lembra Maher (2013), a não existência de políticas também acabaria por ser uma política.

A autora comenta que as políticas linguísticas "se referem a objetivos e intervenções que visam afetar, de uma maneira ou de outra, os modos como as línguas se constituem (...) ou os modos como elas são utilizadas ou, ainda, transmitidas" (MAHER, 2013, p. 119). O campo de estudos de política linguística é "primordialmente um campo de ação política" (RAJAGOPALAN, 2013, p. 34), o que significa que quaisquer ações ou iniciativas relacionadas a decisões sobre línguas não são feitas de forma neutra. Nesse sentido, é preciso questionar o que pode significar a quase onipresença da língua inglesa nos projetos de internacionalização, sendo insistentemente narrada e operacionalizada como a língua (mais legítima) do sucesso acadêmico e mais científica (HAMEL, 2017), apesar de o Brasil estar cercado por países da América Latina e ter em comum relações econômicas, históricas e sociais com esses países, onde se fala espanhol, entre outras línguas. Obviamente, não se pode negar a importância do inglês na produção da ciência. Contudo, concordando com Hamel (2017), considero que o uso dessa língua, reforçado por uma política de bibliometria - de fator de impacto, de aceitação em periódicos internacionais -, que contribui para a naturalização de uma suposta superioridade, acaba invisibilizando outras línguas e criando hierarquias e apagamentos entre quem pode fazer ciência e qual pesquisa importa ${ }^{7}$. No âmbito dessa supervalorização do inglês, promove-se

\footnotetext{
${ }^{7}$ Sem mencionar o fortalecimento da ideia de que o falante nativo é o único que estaria autorizado a falar 
o silêncio epistêmico de outras línguas e do próprio fazer ciência em países que não sejam anglófonos.

A linguística e a área de política linguística tiveram seus papeis atrelados a formas de opressão e controle dos estados-nação, de forma que não foi incomum, ao longo da consolidação do campo das políticas linguísticas, o pensamento de que as políticas linguísticas só teriam lugar se pensadas pelo Estado, de forma top-down (SHOHAMY, 2006). A realidade é que as políticas se dão por todos os lados, quer tenhamos consciência ou não (RAJAGOPALAN, 2013), conforme elucida Shohamy (2006), que as divide em políticas ocultas ou de facto. Quando falamos de política linguística, vem à tona o imbricamento de três dimensões: mecanismos, ideologias e práticas (SHOHAMY, 2006). Shohamy explica que os mecanismos seriam aquilo que conectaria as ideologias às práticas e vice-versa, sendo as primeiras entendidas como as crenças ${ }^{8}$ e representações subjacentes nas políticas linguísticas, enquanto as últimas se referem à ecologia linguística. Em outras palavras, um mecanismo tende a transformar uma ideologia em algo que acontece na prática, em uma política linguística de facto, embora isso nem sempre ocorra: frequentemente, os dizeres de documentos oficiais acabam sendo somente cartas de intenção (SHOHAMY, 2006; MAHER, 2013).

Entre mecanismos importantes mencionados por Shohamy, destacam-se, por exemplo, regras e regulações oficiais, exames de proficiência e políticas educacionais linguísticas (language education policies, ou LEP). Shohamy (2006, p. 77, grifo meu) elucida o papel político, social e econômico que as LEP carregam:

LEP, portanto, não existem sozinhas, mas sim conectadas a dimensões políticas, sociais e econômicas. Enquanto a política linguística diz respeito às decisões que as pessoas tomam sobre línguas e os seus usos na sociedade, LEP se referem aos efeitos dessas decisões em contextos específicos educacionais, escolas e universidades, principalmente em relação a línguas que são consideradas domésticas, estrangeiras ou globais. ${ }^{9}$

\footnotetext{
uma língua (cf. SHOHAMY, 2006; JORDÃO, 2014; JORDÃO; MARTINEZ, 2015).

${ }^{8}$ Partindo da proposta de política linguística de Spolsky (2004), em Language Policy, Shohamy desenvolve sua teoria sobre mecanismos. O conceito de ideologia linguística de Shohamy é o mesmo proposto por Spolsky e chamado de ideologia linguística ou crenças (language ideology ou beliefs).

9 "LEP, then, cannot stand alone but is rather connected to political, social and economic dimensions. While LP is concerned with decisions people make about languages and their uses in society, LEP refers to affecting these very decisions in the specific contexts of education, schools and universities, most often in relation to languages which are considered home, foreign and global."
} 
São esses mecanismos, aqui entendidos como o próprio programa IsF - e, mais especificamente, os cursos operacionalizados pelo NucLi-IsF/Unicamp, que são foco deste trabalho.

\section{CONTEXTO GERAL DE CRIAÇÃO DO ISF E CHEGADA ÀS UNIVERSIDADES ESTADUAIS}

A partir de 2003, devido à gestão do Estado à época, a educação no Brasil passa por várias transformações, na direção de uma democratização do ensino superior. Há a criação de mais universidades federais no interior do país e expansão dos campi nas universidades já existentes, a diversificação de cursos oferecidos e maior oferta de cursos noturnos, além da expansão de instituições privadas e políticas afirmativas para o acesso a essas (CARVALHO, 2014; SANTOS, 2016; C. MARTINEZ, 2018).

Como parte desse cenário, o programa Ciência sem Fronteiras (CsF), criado em dezembro de 2011 pelo governo brasileiro e finalizado em $2015^{10}$, caracterizou-se como "a maior política pública brasileira de envio de pessoas para o exterior, executada em um período curto de tempo" (GRANJA, 2018, p. 19) e almejava promover a "consolidação, expansão e internacionalização da ciência e tecnologia, da inovação e da competitividade brasileira por meio do intercâmbio e da mobilidade internacional ${ }^{11}$ ". O CsF atingiu, principalmente, estudantes de graduação e tinha como meta enviar 100 mil estudantes ao exterior em $4 \operatorname{anos}^{12}$.

Embora "uma política de internacionalização pressup[onha] uma política linguística” (BIZON, 2013, p. 31), o caso do CsF tornou evidente certas ausências relacionadas à política linguística. Uma dessas ausências é notada quando, no primeiro edital do programa, verifica-se grande número de alunos pleiteando vagas em universidades portuguesas, o que poderia ser justificado, entre outras razões, por conveniência,alto custo dos exames de proficiência ou pouco incentivo/acesso ao estudo de outras línguas. Posteriormente, as universidades portuguesas foram removidas da lista de universidades parceiras do programa, para que, segundo o Ministro da Educação da

\footnotetext{
${ }^{10}$ Granja (2018) comenta que a oferta de bolsas foi congelada em 2015, mas foi cancelada somente em 2017.

${ }^{11}$ Disponível em: <http://cienciasemfronteiras.gov.br/web/csf/o-programa> . Acesso em: 20 mar. 2020.

${ }^{12}$ Cf. nota 11.
} 
gestão da época, os alunos desenvolvessem habilidades em outras línguas (SARMENTO et al., 2017). Entretanto, observando chamadas subsequentes ${ }^{13}$, fica evidente que o foco imediato daquele momento seria o inglês, já que o exame de proficiência nessa língua era exigido por grande parte das universidades participantes do programa, mesmo em países que não tinham o inglês como língua materna, como Bélgica e China. Finardi e Guimarães (2017) relatam que, embora houvesse bolsas disponíveis, muitos alunos não demonstravam proficiência suficiente em inglês para que fossem aceitos pelas universidades nas quais pleiteavam vagas.

É nesse contexto que, em dezembro de 2012, institui-se, por meio da Portaria/MEC $\mathrm{n}^{\mathrm{o}}$ 1466, o Inglês sem Fronteiras, um mecanismo de LEP que disponibilizou cursos online de inglês, aplicações do teste de proficiência de língua inglesa TOEFL/iBT e módulos presenciais ministrados pelos NucLis-IsF em universidades federais, todos gratuitos. A criação desse mecanismo implica, como explicitado na seção anterior, uma determinada ideologia linguística, bem como uma perspectiva epistemológica em relação ao processo de internacionalização e o papel das línguas. Quando se nota que os alunos não alcançam as notas necessárias para garantir a mobilidade estudantil, pressuposto-base desse programa, finalmente o olhar dos dirigentes se volta às línguas. Contudo, isso é feito de forma imediatista, privilegiando uma língua dominante - ainda que importante - em detrimento de outras, construindo um discurso que, como discute Hamel (2017, p. 229), “aparece como parte de uma globalização que ocorre sem a intervenção de atores específicos e onde já não há o que possa ser feito" ${ }^{14,}$, de forma "natural, inevitável e inescapável”. Importante destacar que, segundo a Portaria no 1.466 (BRASIL, 2012), somente alunos brasileiros poderiam ser contemplados pelos cursos.

Posteriormente, no final de 2014, o Inglês sem Fronteiras é renomeado Idiomas sem Fronteiras (IsF), sofrendo alterações no rol de línguas ofertadas pelo programa. Objetivando "a valorização do multilinguismo e do multiculturalismo" (ABREU-ELIMA; FILHO, 2017, s.p), afirmação que traz índices de vinculação que poderiam denotar ideologias linguísticas mais progressistas, os seguintes idiomas foram incluídos:

\footnotetext{
${ }^{13}$ Disponíveis no site do CsF: $<$ http://www.cienciasemfronteiras.gov.br/web/csf/inscricoes-resultados $>$, em "Chamadas Encerradas". As chamadas estão separadas por países. Acesso em: 31 jul. 2020.

14 “aparece como parte de una globalización que ocurre sin la intervención de actores específicos y donde ya no hay nada que hacer".
} 
mandarim, japonês, italiano, alemão, espanhol e português para estrangeiros. Conforme descrevem Abreu-e-Lima e Finardi (2019), em 2017 houve um recredenciamento das instituições federais (edital $n^{\circ}$ 29/2017), além da abertura do edital $n^{\circ}$ 59/2017 para universidades estaduais e municipais também poderem participar do programa. Nas duas Chamadas Públicas, as instituições podiam decidir que tipo de NucLi criariam, dependendo de suas instalações e possibilidades: tipo 1 (oferta de inglês); tipo 2 (oferta de inglês e português) e tipo 3 (oferta de inglês, português e ao menos mais um idioma).

A transformação do Inglês sem Fronteiras em Idiomas sem Fronteiras, bem como os editais mencionados acima, criam espaço para outra configuração e finalidade do IsF. Segundo Abreu-e-Lima e Finardi (2019, p. 18), esses editais "constituem evidência do esforço do programa IsF em induzir a proposição de PL para a internacionalização" das instituições de ensino superior que dele participavam. Primeiramente, abriram a possibilidade de que as instituições escolhessem os idiomas oferecidos. Além disso, a oferta de tipo 3 ficaria barrada se o PLA não fosse oferecido. Essa decisão ajuda a fortalecer o papel do ensino de português nas instituições, estratégia que visa ao atendimento de demanda real ou futura, isto é, à oferta de cursos de português também aos estudantes estrangeiros (em intercâmbio de curta duração ou pesquisadores de pós graduação). Adicionalmente, a portaria $n^{\circ} 973$ determina que o objetivo dos cursos seja

propiciar a formação e a capacitação em idiomas de estudantes, professores e corpo técnico-administrativo das Instituições de Educação Superior Públicas e Privadas - IES e de professores de idiomas da rede pública de educação básica, bem como a formação e a capacitação de estrangeiros em língua portuguesa" (BRASIL, 2014),

marcando uma visão não só menos instrumental do ensino de línguas, mas estendida à comunidade acadêmica e à educação básica.

O que se vê, então, nessa segunda fase do IsF, são LEP se tornando oficiais. Entretanto, como já explicitado, tornar oficial não faz dessas intenções políticas de facto. Ainda assim, essas políticas são formas de "promover ou perpetuar determinadas agendas" (SHOHAMY, 2006, p. 78), com impactos a serem medidos em cada instituição, já que para manter NucLis/IsF de tipo 2 ou 3, conforme indicam as portarias, as instituições participantes deveriam oferecer uma contrapartida financeira, enquanto a Capes seria 
responsável somente pelas bolsas dos professores de inglês.

Como explicam Jordão e Martinez (2015), embora o CsF tenha insistido na hierarquização de conhecimentos, invocando uma ordem de importância entre áreas de estudo, pois as bolsas se destinavam somente a alunos de Exatas, percebe-se que a oficialização do IsF tenta trazer luz ao papel das línguas não só na agenda de internacionalização, mas sobretudo nas práticas da comunidade acadêmica e dos professores de rede básica. Além disso, o IsF torna-se responsável não só por um importante passo no caminho da oficialização de diversos mecanismos de políticas linguísticas na universidade, dado que, para se credenciar ao IsF e implantar um NucLiIsF, a instituição necessitaria apresentar um documento de política linguística, mas também vem a promover políticas linguísticas de facto. Tal obrigatoriedade, caracterizada por Abreu-e-Lima e Finardi (2019) como uma "ação indutora" de política linguística, é capaz de impactar potencialmente a oferta de disciplinas para além das já disponibilizadas nos centros de línguas das instituições. Também é possível observar maior atenção dada à formação de futuros professores de diversas línguas ${ }^{15}$, professores bolsistas, e a ampliação da atuação dos professores universitários como gestores dos NucLis-IsF.

Em meio à crise econômica e política ${ }^{16}$, o CsF deixa de existir formalmente em 2017, mas o IsF tem sua continuidade e fomentos garantidos. Como comentam Finardi e Guimarães (2017, p. 604), embora o CsF tenha criado uma "agenda de internacionalização", é o IsF que a consolida, expandindo-se através de vários idiomas e iniciativas. Justamente porque os cursos foram tomando forma baseados nas possibilidades singulares de cada instituição, mensurar o impacto do IsF torna-se difícil, embora diversas pesquisas tenham sido conduzidas, considerando diferentes aspectos (MARTINS; REIS, 2015; ALENCAR, 2019; GUIMARÃES; FINARDI, 2019).

Em junho de 2019, após uma série de ataques e cortes à educação (básica e superior) e à ciência nacional realizados pelo próprio governo federal, o MEC anuncia o fim do $\mathrm{IsF}^{17}$, implicando o cancelamento das ofertas de cursos e das bolsas dos professores, ou seja, a inviabilidade de continuação do projeto, dado que o apoio oferecido

\footnotetext{
${ }^{15}$ Gimenez e Passoni (2016) escrevem sobre o impacto que o IsF teve nas pesquisas apresentadas em três congressos nacionais da área de estudos da linguagem realizados entre 2014 e 2015, apontando que a formação de professores foi o tema mais recorrente.

${ }_{16}^{16}$ Para detalhamento sobre impactos positivos e negativos do CsF e fim do programa, cf. GRANJA, 2018.

${ }^{17}$ Cf. PROGRAMA (2019).
} 
pelo governo era primordial. Até junho de 2019, 96 instituições haviam participado do IsF e, em meados de 2018, na última atualização do site do programa, mais de 364 mil vagas haviam sido ofertadas. Diante do desinteresse do MEC e da Capes em continuar o IsF, em outubro de 2019, o programa passa a ser apoiado como Rede Andifes-Idiomas sem Fronteiras ${ }^{18}$, sendo a adesão a ela opcional a cada NucLi-IsF ${ }^{19}$.

\section{ALGUMAS POLÍTICAS LINGUÍSTICAS DA UNICAMP}

A Unicamp apresenta um longo e importante histórico de cooperação internacional em sua história, como descrevem Tadeu Flores e Cortés (2016). Contudo, foi a partir de 2014 que ela passou a dar especial atenção ao item Programa de Internacionalização, quando este foi incluído no Anuário Estatístico daquele mesmo ano (ASSESSORIA DE ECONOMIA E PLANEJAMENTO, 2014). Outro documento com informações relevantes para a discussão de políticas linguísticas da universidade é o Planejamento Estratégico (Planes) do quadriênio2016-2020, cujas ações de internacionalização propostas para o item Ensino foram:

ampliar ações de internacionalização na graduação, pós-graduação e nos Colégios Técnicos; disponibilizar as ementas e programas das disciplinas em inglês e espanhol; aumentar a oferta de cursos/disciplinas em língua inglesa nas unidades; aumentar a oferta de cursos de português para estrangeiros; aumentar a oferta de ensino de línguas estrangeiras. (UNIVERSIDADE ESTADUAL DE CAMPINAS, 2016, p. 30, grifos meu).

Com relação ao próprio item Programa de Internacionalização presente no Planes, as prioridades apontadas são:

apoiar e adequar-se às estratégias de internacionalização da Universidade, preparando as equipes administrativas para facilitar a vinda de estrangeiros e a ida de alunos, docentes e funcionários para o exterior; intensificar as ações de internacionalização na gestão, formando funcionários bilíngues e investindo em mobilidade em instituições estrangeiras para capacitação. (UNIVERSIDADE ESTADUAL DE CAMPINAS, 2016, p. 45-46, grifo meu).

$18 \quad$ Disponível em: <http://www.andifes.org.br/wp-content/uploads/2020/02/Portaria-deCria\%C3\%A7\%C3\%A3o-da-Rede-IsF-na-Andifes.pdf >. Acesso em: 31 jul. 2020.

${ }^{19}$ No caso específico do NucLi-IsF/Unicamp, o programa não se vinculou à Rede Andifes-IsF. 
No documento, chama atenção a presença de mecanismos de políticas linguísticas que mudariam o papel das línguas através da difusão de informação das ementas a futuros alunos internacionais, bem como da oferta de línguas aos estudantes locais e, imagina-se, funcionários.

Considerando que o foco deste artigo é a política local da Unicamp voltada ao PLA, as informações apresentadas se inserem neste recorte. Houve, até o final de 2019, duas principais LEP na universidade ${ }^{20}$. A primeira delas é o Centro de Ensino de Línguas (CEL) e, a segunda, o NucLi-IsF.

Vale esclarecer que o CEL funciona em moldes diferentes dos centros de línguas de outras universidades, já que esses, em geral, ofertam disciplinas via extensão, frequentemente tendo como professores alunos das diferentes licenciaturas em línguas adicionais. No CEL, os professores são concursados e as disciplinas fazem parte do catálogo de diferentes cursos de graduação da universidade. Nos últimos 20 anos, de acordo com catálogos disponíveis no site da Diretoria Acadêmica, o CEL ofereceu essencialmente as mesmas disciplinas de português, dividindo-as em dois grandes grupos: português para hispano-falantes (níveis I e II) e português para todos os outros alunos estrangeiros (níveis I, II e III).

Segundo o Anuário de 2019, ano-base 2018 (ASSESSORIA DE ECONOMIA E PLANEJAMENTO, 2019), a universidade contabilizava 979 alunos estrangeiros na pósgraduação e 320 na graduação. Já o CEL teve, no primeiro e segundo semestres, 123 e 163alunos matriculados, respectivamente. Embora a universidade receba mais estudantes de pós-graduação, o CEL atende principalmente alunos da graduação, LEP que acaba desvelando uma agenda oculta (SHOHAMY, 2006): uma prática que parece nem dar conta da demanda existente na pós-graduação, nem oferecer disciplinas que contemplem as necessidades específicas desses estudantes.

Na Unicamp, a exigência da proficiência em português para realização de convênios de graduação é fixada em casos específicos, como no Programa de EstudantesConvênio de Graduação (PEC-G), que requer o Certificado de Proficiência em Língua Portuguesa para Estrangeiros (Celpe-Bras).Quanto aos convênios de pós-graduação, a

${ }^{20}$ Há diversos mecanismos funcionando dentro da universidade, como o Instituto Confúcio e o Instituto King Sejong, além do Celpe-Bras. 
exigência depende de cada programa e, quando existe, nunca ocorre no período de ingresso do estudante. Dessa forma, alunos internacionais demonstram diferentes níveis de competência em português: há aqueles que nunca estudaram a língua e aqueles que estudam em cursos de humanidades com interesse particular em países lusófonos ${ }^{21}$. Ressalta-se ainda que as disciplinas regulares, tanto na graduação quanto na pósgraduação, são ministradas preponderantemente em português, indo na contramão do que tem sido feito em várias instituições internacionais, que utilizam o inglês como meio de instrução, mesmo sem ser a língua oficial do país. Outro ponto relevante é que, pelo catálogo dos programas de pós-graduação da Unicamp, a dissertação ou tese podem ser redigidas em português, inglês ou espanhol, mediante autorização da Comissão de PósGraduação $^{22}$.

A segunda LEP relevante que abordo é o NucLi-IsF, que passou a operar na Unicamp após os editais de recredenciamento de 2017, mencionados anteriormente. Com um NucLi tipo 2 (cursos de inglês e de PLA), a Unicamp fez sua primeira oferta de cursos em outubro de 2017 e, conforme, requerido nos editais, criou-se o inédito documento oficial de política linguística da universidade.Como já abordado, o IsF é uma LEP que surge de determinado contexto e que representaria ideologias do Estado a respeito de línguas que importam mais ou menos, que devem ser ensinadas ou não. Ao mesmo tempo, cada NucLi-IsF, ao acumular um documento particular, elaborado por equipes de gestores em cada universidade, também remeterá a diferentes ideologias, não necessariamente pautadas por ideologias do Estado. No caso da Unicamp, o documento foi pensado por professores dos três departamentos do Instituto de Estudos da Linguagem - Linguística Aplicada, Linguística e Literatura -, professores coordenadores do NucLi-IsF e do CEL, e assessoria da Diretoria Executiva de Relações Internacionais, e dispõe sobre diversos aspectos relacionados à internacionalização e ao seu necessário vínculo com uma perspectiva plurilíngue e intercultural.

O NucLi-IsF/Unicamp contava, em 2018, com 11 bolsistas (8 professores na área de inglês e 3 na área de português), matriculados em cursos de graduação ou pósgraduação na área de linguagens. É importante mencionar que, conforme disposto pelo

\footnotetext{
${ }^{21}$ Esse seria o caso, por exemplo, de vários alunos provenientes da China, Coréia do Sul e Japão que geralmente estudam português por dois anos antes do intercâmbio.

${ }^{22}$ Cf. <https://www.pg.unicamp.br/mostra_norma.php?id_norma=3862>. Acesso em: 3 abr. 2020.
} 
próprio programa, enquanto os bolsistas de inglês recebiam bolsas Capes no valor de uma bolsa de mestrado, os bolsistas de português eram subsidiados por uma bolsa criada pela Unicamp, com valor compatível à bolsa da Capes. Por haver tal contrapartida da universidade, quando houve a nota de encerramento do IsF em junho de 2019 e o futuro do programa se tornou incerto, os cursos de português continuaram a ser oferecidos, já que a Unicamp manteve seu compromisso de contrato com os bolsistas até o fim do ano letivo.

Até junho de 2019, o NucLi-IsF/Unicamp havia oferecido, ao longo de 4 semestres, 162 cursos de inglês (com 3489 matriculados) e 23 cursos de português (com 315 matriculados). No segundo semestre de 2019, quando se manteve o oferecimento apenas de disciplinas de português graças à contrapartida da universidade, os cursos foram abertos a migrantes de crise da cidade, contando com a parceria da Secretaria de Cidadania da Prefeitura de Campinas para a divulgação. Isso foi possível devido ao comprometimento com o ensino de português para esse público por parte de uma das coordenadoras do NucLi-IsF, também membro da Cátedra Sérgio Vieira de Mello ${ }^{23}$. A ação, portanto, se coaduna com o Pacto Universitário pela Promoção do Respeito à Diversidade, da Cultura de Paz e dos Direitos Humanos, lançado na ocasião da assinatura da Cátedra pela Unicamp.

Os cursos oferecidos pelo NucLi-IsF/Unicamp variaram entre os níveis básico, intermediário e avançado, com carga horária de 16 ou 32 horas. Parte dos cursos foi sugerida pelo Núcleo Gestor do IsF, enquanto outra parte foi criada pela iniciativa local (marcados com asterisco):

1. Aspectos da cultura brasileira

2. Familiarização com o exame Celpe-Bras*

3. PLE: leitura e produção de textos

4. Cine-debate em PLA: explorando aspectos culturais pela produção cinematográfica brasileira*

5. Leitura e produção escrita para falantes de línguas asiáticas*

6. Letramento acadêmico: produção de resumos*

7. Português língua estrangeira: leitura de textos acadêmicos

8. Produção oral: interações acadêmicas

9. Letramento acadêmico: produção de resumos e artigos científicos*

10. Leitura e produção de textos acadêmicos

\footnotetext{
${ }^{23}$ A Cátedra existe desde 2003 (e na Unicamp, desde 2017) e está em 22 universidades do país. É uma cooperação entre universidades e a agência da ONU para Refugiados (ACNUR) para promover o ensino, a pesquisa e a extensão sobre a temática e também promover a educação para pessoas em condição de refúgio.
} 
Mesmo seguindo uma proposta já observada nos cursos de inglês de outros NucLi$\mathrm{IsF}^{24}$, no sentido de priorizar o ensino de língua para fins acadêmicos ${ }^{25}$, chama atenção que, dos 10 cursos de português ministrados, 5 sejam relacionados aos letramentos $\operatorname{acadêmicos}^{26}$.

Partindo de uma análise preliminar ${ }^{27}$ do perfil dos alunos de dois desses cursos, a saber, Português Lingua Estrangeira: Leitura de Textos Acadêmicos e Leitura e produção de textos acadêmicos, oferecidos em 2018, no primeiro e no segundo semestres, respectivamente, é possível observar, na prática, duas recorrências: (i) maioria de estudantes hispano-falantes (72\%, na turma 2018.1 e $76 \%$, na 2018.2) e (ii) predominância de matrículas de estudantes da pós-graduação $(85 \%$ e $100 \%$, respectivamente).

Nota-se que, em 2018, a instituição recebeu o triplo do número de alunos na pósgraduação, quando comparado à graduação. É notável também o número de alunos que vêm de países onde se fala o espanhol, pois os dados desses dois cursos de português acabam por repetir a tendência do Anuário de 2019: 74\% dos alunos internacionais que vêm realizar a pós-graduação (ou uma parte dela) na Unicamp são hispano-falantes, com grande destaque para aqueles vindo da Colômbia (36\%) e do Peru (18\%).

Acrescento que os cursos de letramentos acadêmicos do NucLi-IsF se configuram como parte de políticas linguísticas de facto, em comparação aos cursos oferecidos pelo CEL, pois atendem a uma demanda por cursos de português com fins específicos, especialmente por parte dos estudantes/pesquisadores hispano-falantes, mas à qual pouca atenção tem sido dada pela universidade e por suas ações de internacionalização. Embora os cursos oferecidos não tenham em seus títulos nenhuma menção ao público falante de espanhol $^{28}$, os cursos tendem a ser escolhidos, como comentam Sarmento et al. (2017),

\footnotetext{
${ }^{24}$ A meu ver, embora muitos dos cursos do IsF sejam voltados para fins acadêmicos, a situação do inglês e do português são diferentes em duas principais medidas: (i) diferença de status das línguas e seu uso nas universidades e (ii) os cursos de inglês serem dados no Brasil, sem que haja, necessariamente, ida dos alunos brasileiros ao exterior, enquanto os cursos de português são para alunos que já estão fora da universidade/país de origem, focando mais em aspectos de interculturalidade, por exemplo.

${ }^{25}$ Cf. SARMENTO et al., 2017.

${ }^{26}$ Killner e Jung (2019, p. 4) argumentam que letramentos acadêmicos "são habilidades linguísticas, orais e escritas que se constituem em práticas sociais próprias do ambiente universitário, as quais pressupõem a apropriação de modelos culturais de falar, escrever, ouvir, de legitimar as vozes sociais, envolve cultura e relações de poder."

${ }^{27}$ Até o momento de escrita deste artigo, somente os dados das turmas descritas estavam disponíveis.

${ }^{28} \mathrm{O}$ que parece elucidar uma política de facto que não se traduz em ideologia no NucLi-IsF/Unicamp, pois
} 
prioritariamente por seus títulos (e raramente pela consulta à ementa), de forma que, no caso aqui apresentado, a presença da palavra acadêmico no título do curso pode ter sido suficiente para despertar o interesse dos estudantes.

Assim como os estudantes possivelmente matricularam-se com base somente no nome do curso, os professores, sob supervisão do coordenador, também partiram desse nome para criar as práticas. Para afirmar precisamente o quanto esses cursos impactam na prática, seria necessário, em pesquisas futuras, considerar ainda outros mecanismos implícitos que constituem essa LEP, tais como material e atividades em sala, além dos professores, agentes dessa política.

Existem ainda outros cursos pensados partindo do contexto local, o que reforça que os mecanismos das LEP podem vir a desenhar e modificar políticas linguísticas de facto, alterando o que é oficial. Como os NucLis-IsF funcionavam autonomamente em cada instituição, as práticas configuraram-se de forma particular em cada universidade, e podese perceber que, no caso do NucLi-IsF/Unicamp, considerou-se o contexto local, partindo de necessidades que refletem, principalmente, o caso de alunos de pós-graduação ou alunos interessados em prestar o Celpe-Bras. Como demonstram Hult e Källkvist (2016, p.61) em pesquisa sobre a pragmaticidade da política chamada "uso de línguas paralelas" na Suécia, também as universidades podem, diante de uma política do Estado, adaptar novas soluções a fim de "incluir seus próprios objetivos e aspirações institucionais para o uso da língua ${ }^{29,}$.

É preciso refletir sobre a importância que as políticas linguísticas de facto representadas pelos cursos voltados aos letramentos acadêmicos podem ter na inserção dos estudantes a médio/longo prazo na universidade e na ciência brasileira. Essas práticas objetivam atender necessidades que não surgem no primeiro momento de acolhimento aos estudantes/pesquisadores, mas sim quando precisam atuar em práticas acadêmicas - desde leitura ou escrita de um artigo em português até participação em redes ou congressos no Brasil. Vale lembrar que os letramentos acadêmicos, por serem práticas sociais, são construídos de formas culturalmente diferentes em cada país - e até em cada área de estudo -, o que reforça a diversidade de experiências nesses espaços de aprendizagem.

embora tenha havido grande presença de alunos hispano-falantes, não houve curso criado para necessidades específicas desse grupo.

29 "encompass their own institutional objectives and aspirations for language use". 
Por fim, considero que a oferta de disciplinas de letramentos acadêmicos é essencial para conceber um projeto de internacionalização que vá na direção do marco plurilíngue proposto por Hamel (2017), em que haja zonas de contatos entre línguas. Dessa forma, quando se promovem tais cursos em português, os mecanismos podem ser usados conscientemente por diversos atores sociais,criando um diálogo entre o que já existe na prática e (futuras) decisões/negociações sobre políticas linguísticas e, consequentemente, sobre língua(gem). Através desse entrelaçamento, busca-se não perpetuar agendas ocultas da língua considerada mais científica ou hegemônica no cenário de internacionalização.

\section{ALGUMAS CONSIDERAÇÕES}

Neste artigo, apresentei o complexo cenário de políticas linguísticas desenvolvidas de forma macro no Brasil através do IsF, assim como um contexto micro impactado por tais políticas através do NucLi-IsF/Unicamp. Movida por uma perspectiva de internacionalização que não sirva à economia do conhecimento (BIZON, 2013; C. MARTINEZ, 2019), procurei explicitar como os mecanismos propostos por Shohamy (2006) podem ser criados e mobilizados para diferentes propósitos, evidenciando ideologias e políticas de facto que podem ir ao encontro de uma internacionalização mais solidária, que promova trocas, cooperações e línguas.

Como mencionei, o processo de internacionalização está ligado ao contexto particular de cada instituição de ensino superior, de forma que não há "receita" para conduzi-lo. Porém, pode-se pensar em projetos de internacionalização que se afastem do conhecimento como mercadoria e da hierarquização de saberes e línguas, como me parece ser o caso dos diversos cursos de letramentos acadêmicos oferecidos no NucLiIsF/Unicamp, que surgem para atender uma demanda local. O contexto da Unicamp certamente poderia dialogar com outros projetos de internacionalização realizados em outras instituições, o que fortaleceria estudos comparativos entre NucLis-IsF e suas políticas linguísticas locais. Também julgo significativo destacar que, com o fim do apoio do MEC e da Capes ao programa, observaremos algum impacto nas políticas linguísticas das universidades - daí a importância de visibilizar as diferentes ações que o IsF pôde implementar em universidades brasileiras. 
Ao longo deste artigo, fica clara a importância das LEP oficiais e o impacto que elas podem ter em diferentes níveis da educação, destacando que elas não funcionam isoladas de contexto - e de investimento, no caso de políticas públicas - e atores nelas implicados. Ao mesmo tempo, como propus com a análise preliminar dos cursos do NucLi-IsF/Unicamp, não se pode, de forma alguma, perder de direção a necessidade, conforme elucida Menezes de Souza (2019, p. 13-14), de pensar a partir do local, "de baixo para cima, partindo do contexto e dos recursos e necessidades de grupos situados".

Finalizo reafirmando o papel do NucLi-IsF/Unicamp como um importante mecanismo de política linguística capaz de impactar no projeto de internacionalização e reiterando que ainda há muitas questões, nesse cenário específico, a ser investigadas em relação ao ensino de PLA e à formação dos professores: Qual é o perfil dos alunos internacionais que estudaram no NucLi-IsF, nos diferentes cursos? Quais seriam suas necessidades específicas? De que forma esses cursos atenderam demandas apresentadas pelos alunos? Como a comunidade externa foi absorvida nos cursos?

Como próximo passo, para abordar tais indagações, pretendo analisar registros obtidos por meio de questionários elaborados pelos professores do NucLi-IsF/Unicamp e respondidos por estudantes de diferentes turmas ao longo de dois anos. Tais análises visibilizariam outras vozes implicadas em políticas linguísticas (oficiais ou não), que teriam muito a acrescentar sobre os cursos de português ofertados, os materiais didáticos elaborados, as abordagens de ensino implementadas, e a própria vida na universidade, sendo possível, assim, em conjunto com diferentes atores sociais,discutir,co-construir e lutar por políticas linguísticas e de internacionalização.

\section{AGRADECIMENTOS}

À Gabriela Pillegi-Provenzano e Daniel dos Santos, professores do NucLi-IsF/Unicamp, por compartilharem informações sobre as turmas mencionadas. O presente trabalho foi realizado com apoio da Coordenação de Aperfeiçoamento de Pessoal de Nível Superior Brasil (CAPES) - Código de Financiamento 001.

\section{REFERÊNCIAS}

ABREU-E-LIMA, D. M.; FILHO, W. B. M. O Programa Idiomas sem Fronteiras. In: SARMENTO, S.; ABREU-E-LIMA, D. M.; FILHO, W. B. M. (org.) Do Inglês sem 
Fronteiras ao Idiomas sem Fronteiras: a construção de uma política linguística para a internacionalização. Belo Horizonte: Editora UFMG, s.p., 2017.

ABREU-E-LIMA, D. M.; FINARDI, K. Políticas linguísticas para internacionalização e o papel do programaidiomas sem fronteiras. In: FINARDI, K.; SCHERRE, M.; VIDON, L. (Orgs.). Língua, discurso e política: desafios contemporâneos. Campinas: Pontes, p. 13$28,2019$.

ALENCAR, T. R. S. Para além das fronteiras: narrativas de professores universitários sobre o lugar do Português como Língua Adicional no Amapá. Dissertação (Mestrado em Linguística Aplicada) - Instituto de Estudos da Linguagem, Universidade Estadual de Campinas, Campinas, 2019.

ANDREOTTI, V. O.; PEREIRA; R. S.; EDMUNDO, E. S. G. Imaginários de educação e de bem público nos discursos de internacionalização do ensino superior. Revista Desempenho, Brasília, n.28, v.1, s.p., 2018.

ASSESSORIA DE ECONOMIA E PLANEJAMENTO. Anuário estatístico da Universidade Estadual de Campinas de 2014. Disponível em: $<$ https://www.aeplan.unicamp.br/anuario/anuario_2014.php>. Acesso em: 01 jul. 2018.

BIZON, A. C. C. Narrando o exame Celpe-Bras e o convênio PEC-G: a construção de territorialidades em tempos de internacionalização. Tese (Doutorado em Linguística Aplicada) - Instituto de Estudos da Linguagem, Universidade Estadual de Campinas, Campinas, 2013.

BRASIL. Ministério da Educação. Gabinete do Ministro. Portaria $n^{\circ} 1.466$, de 18 de dezembro de 2012. Institui o Programa Inglês sem Fronteiras. Diário Oficial da União, Brasília, DF, 19 dez., p. 28, 2012.

BRASIL. Ministro de Estado da Educação. Portaria n ${ }^{\circ}$ 973, de 14 de novembro de 2014. Institui o Programa Idiomas sem Fronteiras e dá outras providências. Diário Oficial da União, Brasília, DF, p. 11-12, 17 nov. 2014.

CARVALHO, C. H. A. Política para a educação superior no governo Lula: expansão e financiamento. Rev. Inst. Estud. Bras., São Paulo, n. 58, p. 209-244, 2014.

CAVALCANTI, M. C. Um Olhar Metateórico e Metametodológico em Pesquisa em Linguística Aplicada: Implicações Éticas e Políticas. In: MOITA-LOPES, L. P. (Org.). Por uma Linguística Aplicada Indisciplinar. São Paulo: Parábola, p. 233-252, 2006.

DE WIT, H. Misconceptions about (the end of) Internationalization: the current state of play. In: JONES, E. et al. (Ed.) Global and Local Internationalization. Rotterdam: Sense Publishers, p. 15-20, 2016.

DLASKA, A. The role of foreign language programmes in internationalising learning and teaching in higher education. Teaching in Higher Education, v.18, n.3, p. 260-271, 2013. 
Disponível em: <http://dx.doi.org/10.1080/13562517.2012.696538>. Acesso em: 03 mar. 2017.

FINARDI, K. R.; GUIMARÃES, F. F. Internacionalização, rankings e publicações em inglês: a situação do Brasil na atualidade. Estudos em Avaliação Educacional, São Paulo, v. 28, n. 68 , p. $600-626,2017$.

GIMENEZ, T.; PASSONI, T. P. Políticas linguísticas e suas consequências não planejadas: o programa "Inglês sem Fronteiras" e suas repercussões nos cursos de Letras. Calidoscópio, v. 14, n. 1, p. 115-126, 2016.

GRANJA, C. D. Internacionalização e mobilidade estudantil: o programa Ciência sem Fronteiras na Universidade Estadual de Campinas. Dissertação (Mestrado) - Universidade Estadual de Campinas, Instituto de Geociências, Campinas, 2018.

HAMEL, R. E. Enfrentando las estrategias del imperio: hacia políticas del lenguaje en las ciencias y la educación superior en América Latina. In: DINIZ, A. G.; PEREIRA, D. A.; ALVES, L. K. A. (org.). Poéticas e políticas da linguagem em vias de descolonização. São Carlos: Pedro \& João Editores, p. 226-261, 2017.

JORDÃO, C. M. ILA - ILF - ILE - ILG: Quem dá conta? Revista Brasileira de Linguística Aplicada, Belo Horizonte, v. 14, n. 1, p. 13-40, 2014.

JORDÃO, C. M.; MARTINEZ, J. Z. Entre as aspas das fronteiras: internacionalização como prática agonística. In: ROCHA, C. H.; BRAGA, D. B.; CALDAS, R. R. (Org.). Políticas linguísticas, ensino de línguas e formação docente: desafios em tempos de globalização e internacionalização. Campinas: Pontes, p. 61-88, 2015.

KILLNER, M.; JUNG, N. M. Letramento acadêmico em contexto de ensino de português como PLE/PLA: uma análise da unidade didática. BELT, v. 10, n. 1, p. 1-14, 2019.

KNIGHT, J. Is Internationalisation of Higher Education Having an Identity Crisis? In: MALDONADO-MALDONADO, A.; BASSET, R. M. (Ed.). The Forefront of International Higher Education: A Festschrift in Honor of Philip G. Altbach. New York: Springer, p. 75-87, 2014.

KNIGHT, J. Five Myths about Internationalization. International Higher Education, n.62, p. 14-15, 2015a.

KNIGHT, J. Five Truths about Internationalization. International Higher Education, n.69, p. 4-5, 25 Mar., 2015 b.

MAHER, T. M. Ecos de resistência: políticas linguísticas e línguas minoritárias no Brasil. In: NICOLAIDES, C. et al. (Org.). Política e Políticas Linguísticas. Campinas: Pontes Editores, p.117-134, 2013.

MARTINEZ, C. A. F. Geografias da mobilidade acadêmica internacional brasileira (ou 
Por que a internacionalização da educação superior é um problema geográfico?). Terra Livre, São Paulo, vol.1, n.50, p.13-33, 2018.

MARTINEZ, J. Z. Entre fios, pistas e rastros: os sentidos emaranhados da internacionalização da Educação Superior. Tese (Doutorado) - Faculdade de Filosofia, Letras e Ciências Humanas, Universidade de São Paulo, São Paulo, 2017.

MARTINS, A.; REIS, E. C.Internacionalização na UFSC: análise do Programa Inglês sem Fronteiras e do curso extracurricular de inglês. In: XV Colóquio Internacional de Gestão Universitária, Mar del Plata. Anais do XV Colóquio Internacional de Gestão Universitária. Argentina, 2015, s.p. Disponível em: $<$ https://repositorio.ufsc.br/handle/123456789/136136>. Acesso em: 24 mar. 2020.

MENEZES DE SOUZA, L. M. "Eu só posso me responsabilizar pelas minhas leituras, não pelas teorias que eu cito". [Entrevista concedida à] Juliana Z. Martinez; Eduardo H. Diniz de Figueiredo. Revista X, Curitiba, vol. 14, n. 5, p. 5-21, 2019.

PENNYCOOK, A. Critical Applied Linguistics: A Critical Introduction. New Jersey: Laurence Erlbaum Associates Publishers, 2001.

PROGRAMA de intercâmbio do MEC que beneficiou 818 mil alunos será fechado. Revista Exame, 19 jul. 2019. Disponível em: <https://exame.abril.com.br/brasil/idiomassem-fronteiras-sera-encerrado-pelo-mec/>. Acesso em: 18 mar. 2020.

RAJAGOPALAN, K. Política linguística: do que se trata afinal? In: NICOLAIDES, C. et al (Org.). Política e políticas linguísticas. Campinas: Pontes, p. 19-42, 2013.

SAMPAIO, H. Internacionalização do ensino superior como área de investigação na América Latina: os casos Brasil, Argentina e México. In: MOURA, R. A.; ALMEIDA, A. A. (org.). Internacionalização do ensino superior: desafios e perspectivas. Curitiba, PR: CRV, p. 93-126, 2016.

SANTOS, B. S. Os processos da globalização. SANTOS, B. S. (Org.). A globalização e as ciências sociais. São Paulo: Cortez, p. 25-102, 2002.

SANTOS, B. S. A Universidade do Século XXI. Conferência de abertura do II congresso de Acadêmicos da Unifesp. $2016 . \quad$ Disponível em: $<$ https://www.youtube.com/watch? $\mathrm{v}=58 \mathrm{~h} 2 \mathrm{Nus} 9 \mathrm{e} 2 \mathrm{w} \&$ list $=\mathrm{WL} \&$ index $=60 \& \mathrm{t}=0 \mathrm{~s}>$. Acesso em: 02 mar. 2020.

SARMENTO, S. et al. IsF e internacionalização: Da teoria à prática. In: SARMENTO, S.; ABREU-E-LIMA, D. M; FILHO, W. B. M. (org.). Do Inglês sem Fronteiras ao Idiomas sem Fronteiras: a construção de uma política linguística para a internacionalização. Belo Horizonte: Editora UFMG, s.p., 2017.

SHOHAMY, E. Language policy: hidden agendas and new approaches. Londres: Routledge, 2006. 
SPOLSKY, B. Language Policy. Cambridge: Cambridge University Press, 2004.

STEIN, S. et al. Towards Different Conversations About the Internationalization of Higher Education. Comparative and International Education, v. 45, n. 1, p. 1-18, 2016.

TADEU FLORES, J.; CORTÉZ, L. 50 Anos de Internacionalização da Unicamp (Universidade Estadual de Campinas). Universidades, México, n. 68, abril-junho, p.65-83, 2016.

UNIVERSIDADE ESTADUAL DE CAMPINAS. Planes - Planejamento Estratégico Universidade Estadual de Campinas 2016-2020. Pró-Reitoria de Desenvolvimento Universitário. Campinas, SP: UNICAMP/PRDU, 2016. Disponível em: $<$ https://www.geplanes.cgu.unicamp.br/geplanes/static/planes_completo.pdf $>$. Acesso em: 20 mar. 2020.

Recebido em: 21 abr. 2020. Aceito em: 13 out. 2020. 